\title{
The role of contrastive intonation contours in the retrieval of contextual alternatives
}

\author{
Bettina Braun and Lara Tagliapietra \\ Max Planck Institute for Psycholinguistics, Nijmegen, the Netherlands
}

\begin{abstract}
Sentences with a contrastive intonation contour are usually produced when the speaker entertains alternatives to the accented words. However, such contrastive sentences are frequently produced without making the alternatives explicit for the listener. In two cross-modal associative priming experiments we tested in Dutch whether such contextual alternatives become available to listeners upon hearing a sentence with a contrastive intonation contour compared with a sentence with a non-contrastive one. The first experiment tested the recognition of contrastive associates (contextual alternatives to the sentence-final primes), the second one the recognition of non-contrastive associates (generic associates which are not alternatives). Results showed that contrastive associates were facilitated when the primes occurred in sentences with a contrastive intonation contour but not in sentences with a non-contrastive intonation. Non-contrastive associates were weakly facilitated independent of intonation. Possibly, contrastive contours trigger an accommodation mechanism by which listeners retrieve the contrast available for the speaker.
\end{abstract}

Keywords: Alternative-set semantics; Contrast; Cross-modal priming; Dutch; Intonation.

“Ben stood up and said: 'I still have some work to do'. He said this in such a way as to imply that I was the one who had nothing to do." ${ }^{\prime 1}$ In reading this

\footnotetext{
${ }^{1}$ First author's translation of the quotation: 'Ben stand auf. Ich muß noch was tun. Er sagte das so, als sei ich derjenige, der nichts tun muß.' (Timm, 2003, p. 156).
}

Correspondence should be addressed to Bettina Braun, Max Planck Institute for Psycholinguistics, P.O Box 310, 6500AH Nijmegen, the Netherlands. E-mail: Bettina.Braun@mpi.nl

We thank Kristin Lemhoefer and two anonymous reviewers for valuable comments on an earlier draft of this paper. Further, we are grateful to Marieke Pompe for providing the Dutch stimuli and contrastive associates and for recording them. 
passage from a novel aloud, the utterance 'I still have some work to do' is probably produced first with a neutral intonation contour (see Figure 1a). However, in light of the last sentence ('He said this in such a way as to imply that I was the one who had nothing to do'), one would probably reread this sentence in a different, contrastive way, accenting the two words $I$ and work (Figure 1b). Such contrastive utterances are part of our daily life. They have two peculiarities. First, they are spoken with a characteristic intonation contour. Second, differently from a neutral realisation, sentences with such a contrastive intonation not only assert a fact (e.g., Ben has to go back to work), but also presuppose contrastive alternatives to the accented words (e.g., someone else doesn't have to work). Although speakers do not explicitly disclose these alternatives, they can become part of the interpretation of the sentence. Apparently, listeners automatically retrieve the alternatives that led the speaker to produce a contrastive utterance. In this paper, we investigated whether a contrastive intonation contour per se triggers a process by which listeners have immediate access to these contextually salient alternatives.

One mechanism available for listeners to deal with lacking background information is called 'bridging' (e.g., Clark, 1977) or 'accommodation' (e.g., Lewis, 1979, Stalnaker, 2002). Accommodation is mainly discussed in the semantics and pragmatics literature and describes 'the phenomenon of accommodating (inserting) something into the context that has not been explicitly mentioned' (Kadmon, 2001, p. 174). It has been argued, for instance, that definite articles presuppose the existence of an entity (e.g., 'I have to pick up my sister from the airport') and factive predicates presuppose the truth of the subordinate clause (e.g., 'He was surprised that he passed the test'). All of the above-mentioned theories deal with the accommodation of a common ground, i.e., a set of propositions that speakers take for granted and encode as such (e.g., the proposition 'I have a sister' in 'I have to pick up my sister from the airport'). We believe that a process similar to accommodation can explain the intuition that listeners generate contextually salient alternatives to contrastively accented words in sentences like ' I still have some WORK to do', in which the prosodic

a)

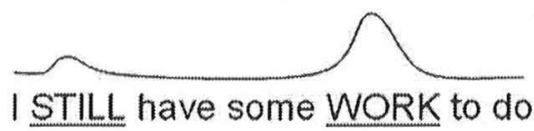

b)

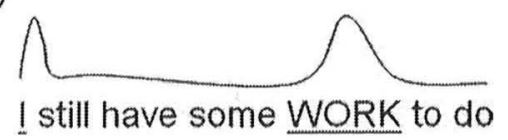

Figure 1. Neutral realisation (a) and contrastive realisation (b). Accents are marked by underscored capitals. 
contour signals that the speaker entertains salient alternatives (e.g., $Y O U$ have NOTHING to do).

Alternatives play an important role in the formalisation of accentuation and narrow focus (Jackendoff, 1972; Rooth, 1992; Steedman, 2000, among others). Adapting an example from Steedman, the sentence 'Marcel discovered a SECRET' is formalised via functional abstraction of the accented word, leaving a variable $x$ ('Marcel discovered $x$ ', or, more formally, $\lambda x$ [discovered'( $x$,Marcel')] $)$. In this semantic formula, $x$ can be replaced by any contextually or situationally available alternative, resulting in so-called alternative sets (such as \{Pluto, a cookie, three dimes\} in this example). These alternative sets are more restricted for sentences with a narrow, contrastive focus in which only the focused constituent (i.e., 'a secret' in the above example) contributes new information. Narrow focus sentences serve as answers to specific questions such as 'What did he discover?' Therefore, the alternatives usually have the same syntactic class as the focused constituent (a noun phrase in this example) and belong to the same semantic class ('something that can be discovered' in this example). In contrast, alternative sets become much more varied for sentences with a larger focus domain, such as a verb phrase focus or sentence focus (responses to questions like 'What did he do?' or 'What happened?').

In the experiments that follow we investigated whether this way of formalising sentences with a narrow focus has any psychological reality, i.e., we tested whether relevant contextual alternatives become immediately salient for listeners upon hearing sentences with a contrastive intonation contour. Note that there are already a number of studies that investigated the interpretation of sentences with contrastive intonation contours. Listeners, for instance, successfully exploit intonational information to determine whether the speaker intends to continue with the previously mentioned referent or whether s/he will introduce a new, contrasting one. In an eyetracking experiment, Dahan, Tanenhaus, and Chambers (2002) used a sequence of two instructions (e.g., 'Move the candle above the triangle. Now move the candy below the square') and asked their participants to click on the respective target object (e.g., 'candy'). An accented referent in the second instruction (e.g., 'Move the candle above the triangle. Now move the CANDY below the SQUARE') led to more fixations to the new, as-yet unmentioned object (e.g., 'candy') compared with an unaccented referent. Since these effects were observed before the speech signal unambiguously identified the target, they can only be attributed to the different prosodic realisations of the instructions. Similarly, upon hearing two instructions (e.g., 'Click on the purple violin. Now click on the red violin') an accented adjective in the 2 nd instruction (e.g., 'RED violin') results in more fixations to an object of the same type as in the first instruction (e.g., 'violin') than to another red object (e.g., 'vase') displayed on the screen (Ito \& Speer, 2008; 
Weber, Braun, \& Crocker, 2006). Interestingly, listeners not only make use of pitch accent distribution (i.e., accentuation of referent or adjective) but also appear to be sensitive to pitch accent type: A contrastive pitch accent such as $\mathrm{L}+\mathrm{H}^{*}$ (high pitch on the stressed syllable preceded by a low tone which results in a steep rise to the peak) creates a strong bias towards contrastive referents, while $\mathrm{H}^{*}$ signals both new and contrastive referents (Watson, Tanenhaus, \& Gunlogson, 2008). Taken together, these results show that listeners use intonational contrast marking and the situational context (e.g., the objects in the computer display) to identify the intended referents (i.e., new referent, same type of object, or contrastive referent).

However, the results of these eye-tracking studies cannot answer the question whether listeners have access to contrastive alternatives that are not explicitly available, i.e., when contrastive sentences are produced without sufficient context (e.g., ' I still have some WORK to do'). Therefore, it is largely unknown how listeners process such sentences, which occur frequently in everyday conversation. The issue, however, can be addressed with the cross-modal associative priming paradigm (Swinney, Onifer, Prather, \& Hirschkowitz, 1979; Tabossi, 1996). Differently from eye-tracking experiments, this technique does not offer a preceding context in which contrastive alternatives are explicitly provided. Through these means, implicit rather than explicit alternative processing can be studied. In crossmodal priming experiments, participants first hear a prime (e.g., a word) and then usually perform a lexical decision task on a visually presented target word. Priming effects result in faster lexical decisions (e.g., to CAT) after related auditory primes (e.g., dog) than after unrelated ones (e.g., bus). ${ }^{2}$

Recently, Norris, McQueen, Cutler, and Butterfield (2006) provided compelling evidence that associative priming is not due to an automatic mechanism following lexical access. Rather, this technique taps into the processing occurring at the level of conceptual representation of the current interpretation of the utterance. Therefore, cross-modal associative priming is sensitive to semantic effects of the context. For example, providing a discourse context incoherent with the association between the prime and the target hampers the recognition of related visual targets (Blutner \& Sommer, 1988; Tabossi, 1988; Williams, 1988). Williams (1988), for instance, found priming for visual targets (e.g., TABLE), when primes (e.g., chair) were presented in isolation; in random word lists (e.g., 'when brass heard could in that only land as more film to interested to is chair because which came could all ice in'); and in sentences related to the targets (e.g., 'The man entered the dining room and sat down on a chair in eager anticipation of a hearty meal'). On the other hand, priming was not observed when the prime

\footnotetext{
${ }^{2}$ Throughout this article, auditory primes will be marked by italics and visual targets by capitals.
} 
occurred in sentences that were unrelated to the target (e.g., 'The man found that he could only reach the best apples by standing on a chair because they were all so high up'). Similarly, Tabossi (1988) reported facilitation for visual targets (e.g., FAT) only when sentences underlined aspects of the primes' meaning related to the target (e.g., 'To follow her diet, the woman eliminated the use of butter'); however, there were no reliable effects when the sentences focused on features unrelated to the target (e.g., 'To soften it, the woman heated a piece of butter'). Associative effects are hence subject to the presence of a relevant or 'effective context' (Foss \& Ross, 1983; Williams, 1988), which is part of the current interpretation of the utterance (Norris et al., 2006).

More importantly, cross-modal associative priming appears to be sensitive to prosodic effects. A contrastive intonation contour is one of the factors that may encourage deeper semantic processing and hence lead to priming effects (Norris et al., 2006). In Experiment 4C, Norris et al. presented sentences (e.g., 'He suggested that it was really the date of the election that mattered') with a contrastive accent on either the prime (e.g., 'date') or on another word later in the sentence (e.g., 'election'). The visual targets were presented at the offset of the prime (e.g., 'date'). Priming effects for related targets (e.g., TIME) were detected for both conditions, but were stronger and more reliable after accented primes than after unaccented ones. However, these results cannot be solely attributed to contrastive accentuation as most of the experimental sentences contained syntactic and lexical presupposition triggers (e.g., 'We hoped that ...', 'The odd thing was ...') or focus particles (e.g., 'It was only when') that might have drawn listeners' attention to the part of the sentence containing the prime. Therefore, it is conceivable that priming was encouraged also by the syntactic constructions used and not solely by contrastive pitch accents.

Hence, it is still an open question if a contrastive pitch accent per se can serve as an 'effective context' for the recognition of words, and in particular, whether a contrastive pitch accent facilitates the recognition of contrastive alternatives. In two cross-modal priming experiments we investigated the effect of a contrastive intonation on the recognition of words associated to sentence-final primes (e.g., flamingo, 'flamingo'). The associated words were either contrastive alternatives (e.g., PELIKAAN, 'pelican'; henceforth: contrastive associates), or generic associates that are not contrastive alternatives (e.g., ROZE, 'pink'; henceforth: non-contrastive associates). More specifically, in Experiment la we tested whether contrastive alternatives are easier to recognise upon hearing a sentence with a contrastive intonation contour than after hearing a sentence with a non-contrastive one. In Experiment $1 \mathrm{~b}$ we tested the effect of the same prosodic contours on the recognition of non-contrastive associates to ascertain whether this effect is 
specific for contrastive alternatives or whether a contrastive intonation in general makes all kinds of related words more easily accessible.

As contrastive intonation contour we chose a double contrast ('A did B but $\mathrm{X} \operatorname{did} \mathrm{Y}^{\prime}$ ), resulting in a contrast on the first constituent and on the sentence-final prime. Sentences with such a double contrast are unambiguously contrastive (Braun, 2005, 2006), while sentences with only one accent on the sentence-final noun (e.g., 'Marcel discovered a SECRET') may be perceived as ambiguous between a narrow-focus interpretation and a broadfocus interpretation (Bartels \& Kingston, 1994; Birch \& Clifton, 1995; Ladd, 1983; Welby, 2003). Furthermore, the number and the positions of accented words can be matched in sentences with a double contrast and sentences with a hat pattern, which is the most frequent neutral intonation contour in Dutch (Cohen \& 't Hart, 1967; 't Hart, Collier, \& Cohen, 1990; see Figure 2a for an illustration). The neutral hat pattern consists of a pitch rise on the first accented word, a slightly declining high plateau, and a fall on the second accented word (see Figure 2b). In our materials, the rise and the fall in the

(a)

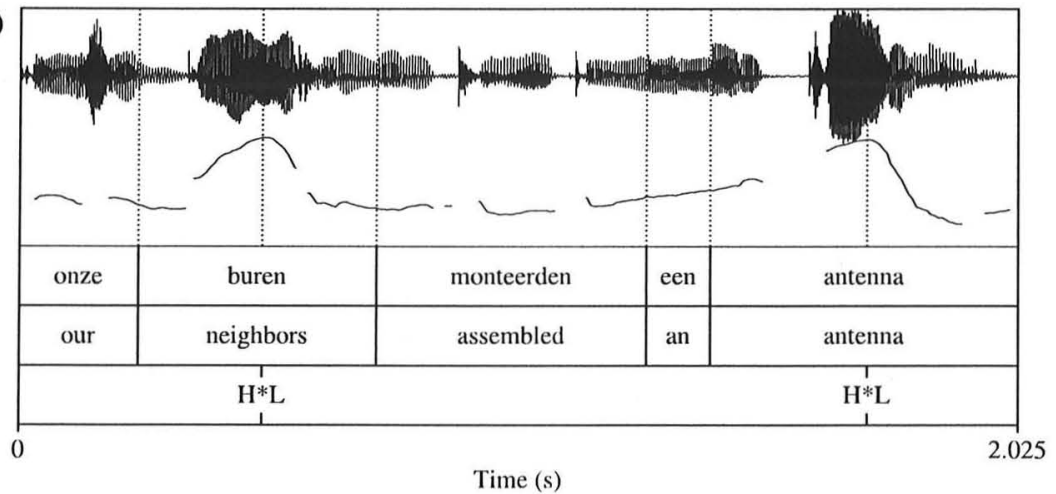

(b)

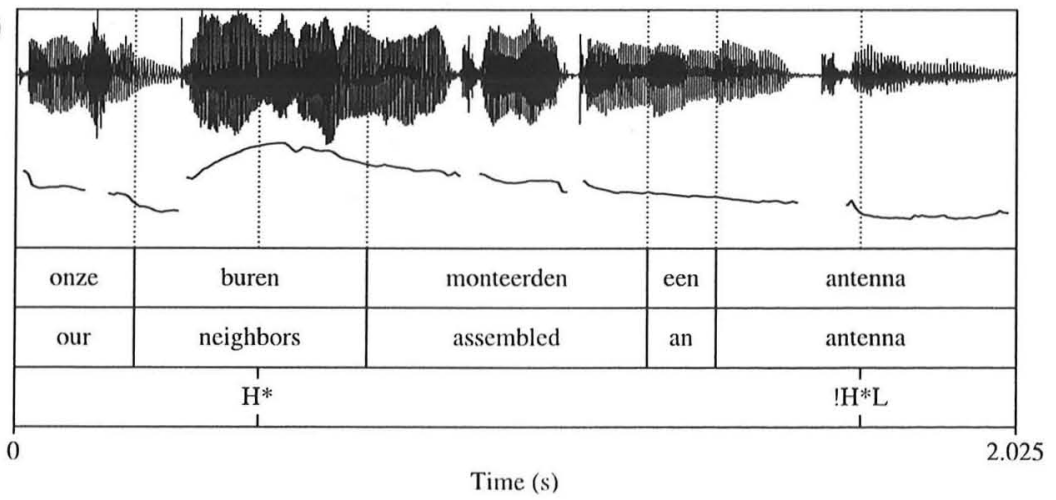

Figure 2. Examples of the hat pattern intonation contour in the non-contrastive condition (a) and of the double peak contour in the contrastive condition (b). The intonational annotation for the sentences following ToDI (Transcription of Dutch Intonation, see Gussenhoven, 2005) is provided on the third tier. 
non-contrastive hat pattern are realised on the same words as the two pitch falls in the contrastive intonation contour (on the first content word in the sentence and on the sentence-final word respectively). Hence, the only difference between the two intonation contours is the type of pitch accent on the accented words - i.e., the exact tonal realisation - and not the number or the position of the accented words.

If the semantic formalisation of contrastive focus using alternative sets has any cognitive relevance, we would expect contrastive associates to be more easily accessible and hence facilitated upon hearing a sentence with a contrastive intonation contour but not upon hearing a sentence with a noncontrastive intonation. This explanation only holds, however, if the recognition of non-contrastive associates is not affected by a contrastive intonation contour. If the recognition of non-contrastive associates is modulated by sentence intonation in the same way as the recognition of contrastive associates, then contrastive intonation contours make all kinds of associates more accessible (Norris et al., 2006).

\section{Methods}

Materials. Thirty-six quadruplets of Dutch words were selected to use as experimental items. Each quadruplet comprised a related prime (e.g., flamingo, 'flamingo'), a contrastive associate to the related prime (e.g., pelikaan, 'pelican'), a non-contrastive associate to the related prime (e.g., roze, 'pink') and a control prime that was unrelated to each member of the quadruplet (e.g., beroemdheid, 'celebrity'). These quadruplets were created with the following procedure.

Eighty high frequency ( $>0.07$ occurrences per million) Dutch tri-syllabic mono-morphemic nouns with stress on the second syllable were extracted from the CELEX word form dictionary (Baayen, Piepenbrock, \& Gulikers, 1995) for use as potential related primes. Words with large alternative sets (e.g., proper names, places, etc.) were avoided. These 80 related prime candidates were used in a free association web experiment, in which 31 Dutch participants had to produce one free associate in response to each given stimulus. Words that did not elicit a clear associate (i.e., one given by less than $25 \%$ of the participants), words that resulted in two equally frequent associates, and words for which participants provided a contrastive alternative (a word of the same word type and semantic class that could be used in sentences such as 'He didn't buy $\mathrm{X}$ but $\mathrm{Y}$ ') were discarded. This selection resulted in 44 related primes that had a frequent non-contrastive associate (produced by $39 \%$ of participants, on average). A Dutch native speaker constructed 44 syntactically and semantically neutral sentences (i.e., word orders that do not induce a contrast) that ended in these potential primes. Most of them were subject-verb-object sentences (e.g., 'Our 
neighbours assembled an antenna'), but there were also three with a preverbal preposition phrase (e.g., 'On Saturday I went to the theatre'), two with an expletive (e.g., 'There was air-conditioning in the cabin'), and two passive constructions (e.g., 'The inflammation was caused by a bacteria'). Further, a semantic alternative for each word in this context to use as contrastive associates was selected (e.g., 'dish' for 'antenna' - which are both means to receive broadcast, 'virus' for 'bacteria' - which are both sources for infection). The association strength between the 44 related primes and their contrastive and non-contrastive associates was then tested in a web-based rating experiment with 20 Dutch participants. Every participant rated a total of 88 words, 44 related ones, and 44 unrelated ones. Each participant rated the relationship between the prime and either the contrastive or the non-contrastive associate (on a scale from 1, 'unrelated' to 7, 'strongly related'). Then, 36 triplets were selected from the set of 44 so that the association strengths of the related primes with the contrastive associate $(M=5.5, S D=0.77)$ and with the non-contrastive associate $(M=6.2, S D=0.55)$ were as balanced as possible. Nevertheless, the relatedness scores for non-contrastive associates were significantly higher than for contrastive ones, $t(35)=4.9, p<.0001$.

The contrastive associates appeared as visual targets in Experiment 1a, and the non-contrastive associates appeared as targets in Experiment 1b. The mean frequency of the eventually selected 36 related primes was 8.6 occurrences per million (o.p.m.), $S D=11.3$, according to the CELEX database. Contrastive targets were 7.8 letters long on average and had a mean frequency of 19.0 o.p.m. $(S D=54.2)$. Non-contrastive targets were 5.5 letters long with an average frequency of 115.2 o.p.m. $(S D=203.0)$. Given the elicitation procedure for non-contrastive associates and the constraints on the selection of contrastive associates, the lexical frequency and number of characters could not be matched. Contrastive associates were significantly longer than non-contrastive ones, $t(35)=4.22, p<.0001$, and less frequent, $t(35)=2.77, p<.01$.

Finally, for each related prime and its (contrastive and non-contrastive) associates, a control prime unrelated to all three was chosen. Similar to the related primes, control primes were all tri-syllabic words stressed on the second syllable (mean frequency of 10.5 out of a million, $S D=23.4$ ); further, control primes could be inserted in the same sentence as their paired related primes. Durations of the experimental and control primes (divided by the respective utterance durations to account for speech rate) did not differ across the two intonational realisations, $t(35)=1.66, p>.1$ for experimental primes, $t(35)=0.21, p>.8$ for control primes. Experimental primes lasted on average $37.8 \%$ of the overall utterance duration, control primes $38.5 \%$. All the experimental materials are listed in Appendix 1. 
Further, 164 filler sentences and six practice sentences were constructed, structurally and semantically similar to the experimental ones. Eighteen of the filler items had a non-word visual target that was phonologically related to the sentence-final word, 92 had a non-word visual target unrelated to the sentence-final word, and 54 had an existing word as visual target that was unrelated to the sentence final word. The six practice sentences were paired with three word and three non-word visual targets. Filler and practice targets were matched to the experimental targets in terms of the distribution of the number of characters.

All the sentences were recorded by a trained female speaker of Dutch in a soundproof room and directly digitised onto a PC (44 kHz, 16 bit). She read the 36 experimental sentences and the 36 control sentences both neutrally, resulting in a declining hat pattern as shown in Figure 2a, and with a double contrast realised on the first content word of the sentence and the sentencefinal prime (Figure $2 b$ ). The contrastive intonation was cued by a contrastive precursor and a contrastive connector (e.g., 'WE assembled a SATELLITE dish, but ...'). Half of the filler sentences and half of the familiarisation sentences were recorded with a non-contrastive and half with a contrastive intonation contour. As can be seen in Figure 2, the f0-excursion of the pitch fall on the sentence-final prime word was significantly larger in sentences with a contrastive intonation contour than in sentences with an noncontrastive one, $t(71)=48.6, p<.0001$. The excursion was on average 180.0 $\mathrm{Hz}$ for contrastive contours compared with $36.3 \mathrm{~Hz}$ for non-contrastive ones. $^{3}$

Participants. Eighty Dutch students from the Radboud University Nijmegen, unaware of the purpose of the experiment, participated for a small fee, 40 in each experiment. They had not taken part in the earlier web experiments, had good or corrected vision and no history of hearing problems.

Procedure. Participants were tested individually in a soundproof cabin sitting in front of a computer screen. Each sentence was played in stereo at a comfortable volume via headphones. The visual target appeared in white Arial 72pt characters on black background immediately after the end of the sentence. Participants received written instructions, in which they were asked to press the right button when the string of letters they saw on the screen was a Dutch word or proper name and the left button when it was not. Lefthanded participants had to press the left button for 'yes'-responses.

\footnotetext{
${ }^{3}$ The f0-values were extracted from the middle of the stressed and post-stressed vowel for contrastive contours and in the middle of the pre-stressed and stressed vowel for non-contrastive contours.
} 
Responses slower than 2 seconds after the appearance of the visual target were not recorded.

Four experimental lists were constructed by rotating through the four conditions, crossing the two within-subjects, between-items factors intonation of the target sentence (contrastive or non-contrastive) and prime type (control or related). There were hence nine items per condition. Each list further contained all the practice and filler items, totaling in 206 trials. Two orders were made for each list, avoiding the possibility that two or three subsequent sentences could be interpreted as part of a coherent discourse. Participants were randomly assigned to one of these lists.

\section{Results}

Due to an oversight, one control prime was identical to one of the related primes. The two pairs containing these primes were therefore excluded from the analyses.

Experiment la - contrastive associates. Six trials were excluded because there was no button press (timeout) and an additional 55 trials were discarded because of an incorrect response. Errors were distributed evenly across conditions and participants. Reaction times for the remaining trials were log-transformed. One participant with exceptionally long reaction times (mean log-RT larger than 2 standard deviations from the overall mean) was not included in the analysis.

Log-RTs within 2 standard deviations of the mean were analysed (range 5.88 to 6.91) using mixed-effects models with participants and items as crossed random factors, and contrast coding for factors $(N=1280)$. This analysis has been chosen over the more traditional separate subject and items analyses as it is less dependent on normality and sphericity assumptions, can cope well with missing data, and allows for the combined analysis of categorical and continuous predictors (e.g., Baayen, 2008; Barr, 2008; Jaeger, 2008; Quené \& van den Bergh, 2004). The crucial predictors were intonation (contrastive or non-contrastive) and prime type (control or related prime). Further, the model included a number of predictors that have been shown to affect reaction times in lexical decision experiments, such as log-lexical frequency as extracted from the CELEX word form dictionary, number of characters, the reaction time to the preceding trial, whether the preceding filler trial had a word or non-word target, and the correctness of the preceding response.

The initial model included all predictors and the interaction between intonation and prime type. Predictors with a $p$-value larger than .1 were removed if this did not deteriorate the fit of the model (as estimated by a likelihood-ratio test). The log-likelihood of the full model was 405.5, that of 
the final model $405.9\left(\chi^{2}=0.85, \mathrm{df}=2, p>.5\right)$. Then, the more parsimonious model was refitted. Data points with residuals larger than $2.5 S D$ were removed. Resulting $p$-values were estimated as the posterior probability of a Markov Chain Monte Carlo (MCMC) simulation with 10000 runs. The results of the final model are summarised in Table 1.

As expected, responses were slower to visual targets with more letters and for which the reaction time to the preceding filler trial was longer. Crucially, results for the contrastive visual targets showed a significant interaction between the intonation of the sentence and the relation between prime and target. Responses were on average $19.3 \mathrm{~ms}$ faster after related primes if the sentence containing the prime was spoken with a contrastive intonation contour. There was no facilitation for contrastively related visual targets when sentences had a neutral intonation contour. The mean RT for each condition, calculated on the basis of the statistical model for a mean reaction time to the preceding filler trial (6.47) and a median number of characters for the target (8), are illustrated in Figure 3.

Experiment $1 b$-non-contrastive associates. Twenty trials with incorrect responses were discarded. Log-RTs within $2 S D$ of the mean were analysed (range 5.85 to $6.79, N=1290$ ). The fitting procedure and predictors were the same as described for Experiment 1a. The log-likelihood of the full model was 588.6 compared with 590.1 for the final model $\left(\chi^{2}=2.9\right.$, $\left.\mathrm{df}=4, p>.5\right)$. Results of the final model are summarised in Table 2.

Similar to Experiment 1a, responses were slower to visual targets with more letters and for which the reaction time to the preceding filler trial was longer. Furthermore, responses were faster to targets with a higher lexical frequency. Moreover, results for the non-contrastive associates showed a main effect for prime type only. Responses were on average $8.4 \mathrm{~ms}$ faster

TABLE 1

Estimates, confidence intervals, and p-values for Experiment 1a. Positive estimates indicate the amount of increase in log-RT relative to the Intercept. For factors, the change from the Intercept applies for the level given in italics.

\begin{tabular}{lrccc}
\hline & Estimate & Lower Bound & Upper Bound & $p(M C M C)$ \\
\hline Intercept (non-contrastive intonation, & 5.732 & 5.457 & 6.015 & .0001 \\
$\quad$ unrelated prime) & & & & \\
Intonation (contrastive) & 0.006 & -0.017 & 0.029 & $n s$ \\
Prime Type (related) & 0.008 & -0.015 & 0.032 & $n s$ \\
Previous Log-RT & 0.070 & 0.030 & 0.111 & $<.001$ \\
$\quad$ Number of characters & 0.028 & 0.016 & 0.038 & $<.0005$ \\
Intonation: Prime Type (contrastive & -0.039 & -0.073 & -0.007 & $<.05$ \\
$\quad$ intonation, related prime) & & & & \\
\hline
\end{tabular}




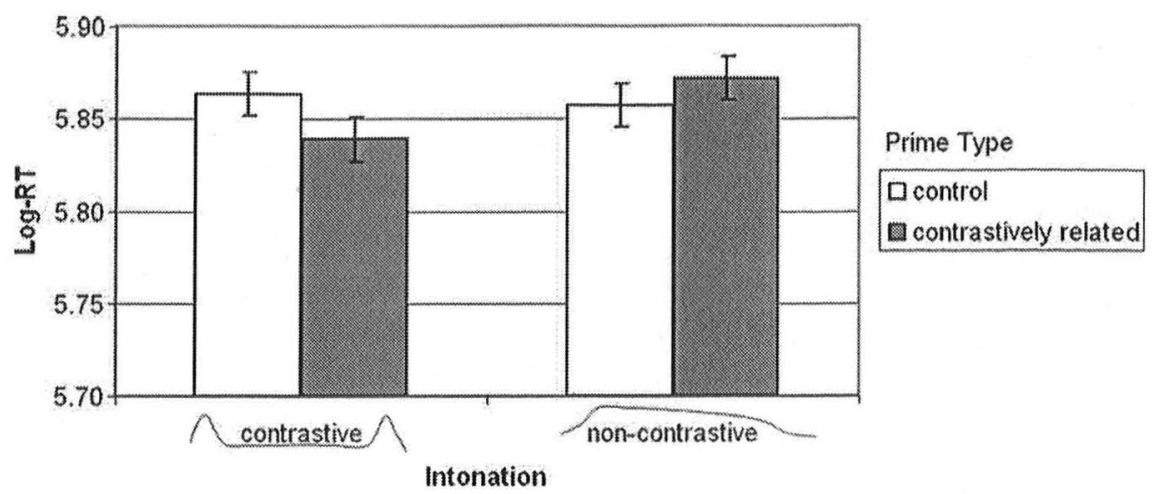

Figure 3. Mean Log-RTs for Experiment la (contrastive visual targets) as a function of the experimental conditons: intonation (contrastive vs. non-contrastive) and Prime Type (control vs. related). Error bars represent standard error.

when the auditory prime was related to the visual target than when it was not (on average $538.1 \mathrm{~ms}$ for control primes compared with $529.7 \mathrm{~ms}$ for related ones). There was no effect of intonation, $p(\mathrm{MCMC})>.5$, and no interaction between intonation and prime type, $p(\mathrm{MCMC})>.25$. The recognition of generically related visual targets is hence independent of the intonation contour. There is a weak facilitation for related primes, which is consistent with earlier findings in cross-modal priming. ${ }^{4}$

Note that upon hearing a sentence with a contrastive intonation contour the priming effect for non-contrastive targets is smaller than for contrastive ones $(8.4 \mathrm{~ms}$ vs. $19.3 \mathrm{~ms})$, despite the fact that the non-contrastive targets had a stronger relation to the prime than the contrastive ones. The results of the two experiments cannot be directly compared, however, because of the

TABLE 2

Estimates, confidence intervals, and $p$-values for Experiment $1 \mathrm{~b}$.

\begin{tabular}{lrrrc}
\hline & Estimate & Lower Bound & Upper Bound & $p(M C M C)$ \\
\hline Intercept (non-contrastive intonation, & 5.645 & 5.366 & 5.910 & .0001 \\
$\quad$ unrelated prime) & & & & \\
Prime Type (related) & -0.016 & -0.031 & -0.002 & $<.05$ \\
Previous Log-RT & 0.114 & 0.074 & 0.152 & .0001 \\
Number of characters & 0.009 & 0.003 & 0.016 & $<.01$ \\
Log-Freq & -0.019 & -0.027 & -0.011 & .0001 \\
\hline
\end{tabular}

\footnotetext{
${ }^{4}$ Note that while contrastive visual targets were uniformly nouns, four of the non-contrastive visual targets had a different part-of-speech ( 3 adjectives and 1 verb). This non-uniformity in part-of-speech might influence the priming effects. However, excluding those items does not change the results in any way, so we report the statistical analysis of all items.
} 
lexical differences of the targets across experiments. As reported in the Materials section, non-contrastive targets were shorter and more frequent than the contrastive associates. These differences are probably the reason that participants responded on average $55.9 \mathrm{~ms}$ faster to non-contrastive targets than to contrastive ones, $t(2488.7)=11.4, p<.001$, since mean responses per participant for filler trials did not differ across experiments, $t(78)=0.1, p>.9$.

\section{GENERAL DISCUSSION}

In two cross-modal priming experiments we manipulated sentence intonation (contrastive vs. non-contrastive) and the relation between prime and visual target (unrelated vs. contrastively and non-contrastively associated). Results showed that contrastive associates - which are contextual alternatives to the primes - are facilitated only when the primes are realised in sentences with a contrastive intonation. On the other hand, non-contrastive associates which are generic associates that are not contextual alternatives - are weakly facilitated independent of the intonation contour. These results show that a contrastive intonation contour modulates the interpretation of a sentence. In particular, the present results indicate that only a contrastive interpretation of the sentence makes contextually relevant alternatives more accessible and hence easier to recognise.

The observed facilitation of contrastive associates upon hearing a sentence with a contrastive intonation contour appears to be genuinely driven by the interpretation of sentences with a contrastive intonation contour. This effect cannot be simply explained by a more salient production of the primes in sentences with a contrastive intonation. If this explanation were correct, the presence of the larger pitch movement would have also affected the recognition of the non-contrastive associates in Experiment 1b. However, no interaction of prosodic contour and primetarget relation was detected in the second experiment. Also, this effect cannot be explained by the fact that contrastive, category associates generally elicit stronger priming than non-contrastive ones, even when they are barely related to the prime (Fischler, 1977 and Lupker, 1984 for visual-visual priming; Moss, Ostrin, Tyler, \& Marslen-Wilson, 1995, for auditory-auditory priming). If this were the case, contrastive associates should have also been facilitated in sentences with a non-contrastive intonation contour.

Finally, one might argue that a contrastive intonation contour only serves the function of attracting attention to the accented words and therefore makes less strongly related associates (i.e., the contrastive associates in this study) also accessible. This explanation would predict the same interaction 
observed for contrastive associates also for those non-contrastive associates that are only weakly related to the auditory prime. To test this hypothesis, we split the non-contrastive associates into two halves, highly related ones (rating $>6.3$ ) and weakly related ones (rating $\leq 6.3$ ). The weakly related items had a mean rating of $5.8(S D=0.60)$-compared with a mean rating of $5.5(S D=0.77)$ for the contrastive associates. These weakly related noncontrastive associates were analysed using the same model as for the contrastive associates. There were neither main effects of intonation or prime type, nor an interaction between the two factors, $p(\mathrm{MCMC})>.5$. The lack of interaction between intonation and prime type for the weakly related non-contrastive associates suggests that a contrastive intonation contour does not simply have a highlighting function by which less strongly related associates become more accessible. Therefore, it appears more plausible that a contrastive intonation contour especially makes contextually sensible alternatives to the accented words salient.

The present findings support and extend the conclusion drawn by Norris et al. (2006) that prosody alters the interpretation of the sentence. Using syntactically and semantically neutral sentences we could show that prosody per se acts as an 'effective context' (Williams, 1988) and affects sentence interpretation. Furthermore, the effect of prosody proved to be extremely specific. Only contrastive alternatives were facilitated by a contrastive realisation, whereas non-contrastive associates were available for both contrastive and non-contrastive intonation contours. The present results also extend previous findings from the eye-tracking literature. The observed facilitation of contrastive alternatives upon hearing isolated sentences with a contrastive intonation contour shows that contrastive alternatives become accessible even in the absence of linguistic or pragmatic context.

From an intonational perspective, the present data suggest that during the processing of utterances with a non-contrastive intonation contour, only highly related associates (i.e., non-contrastive associates which had a higher rating than the contrastive ones) become accessible and hence are recognised faster. During the processing of utterances with a contrastive intonation, contrastive associates (i.e., contextual alternatives to the accented items) become also salient.

From a linguistic or pragmatic perspective, the present findings support the use of alternative sets to formalise contrastive focus. In sentences with a contrastive intonation contour, in which the alternative sets to the accented words are rather small and of a restricted type, listeners rapidly generate salient contextual alternatives. On the contrary, for sentences with a noncontrastive intonation contour these alternatives are not immediately accessible. 
Differently from sentences with only one accent on the sentence-final noun (e.g., 'Marcel discovered a SECRET'), which can be interpreted as neutral or contrastive, the double-peak contour employed in this study (e.g., " MARCEL discovered a SECRET) unambiguously signals contrast. This prosodic contour, however, encodes contrastive alternatives for both accented words, so that listeners potentially retrieved alternatives for both the sentence-final prime and for the sentence-initial constituent. The additional alternative set for the sentence-initial words may have decreased the facilitation of the contrast associates. Therefore, in sentences with a single contrast on the prime only, this effect might have been larger.

Taken together, the present experiments support the intuition that contrastive accentuation on a word makes contextual alternatives to that word salient to the listener. The fact that salient alternatives are generated upon hearing isolated sentences is especially noteworthy, as listeners frequently encounter utterances that are not sufficiently grounded, i.e., for which the speakers did not provide all the relevant background information beforehand. We suggest that this is due to an accommodation mechanism, through which listeners adopt assumptions implicit in the speaker's use of contrastive marking and generate plausible alternatives. Our data suggest that this accommodation mechanism is automatic and occurs early in the recognition process. Once more, language proves to be an efficient means of communication, as listeners effortlessly exploit prosodic information to accommodate the information that the linguistic structure does not explicitly encode (e.g., contextual alternatives).

\section{REFERENCES}

Baayen, R. H. (2008). Analyzing linguistic data: A practical introduction to statistics using $R$. Cambridge: Cambridge University Press.

Baayen, R. H., Piepenbrock, R., \& Gulikers, L. (1995). The CELEX lexical database [CD-ROM]. Philadelphia, PA: Linguistic Data Consortium, University of Pennsylvania.

Barr, D. J. (2008). Analyzing 'visual world' eyetracking data using multilevel logistic regression. Journal of Memory and Language, 59, 457-474.

Bartels, C., \& Kingston, J. (1994). Salient pitch cues in the perception of contrastive focus. In P. Bosch \& R. van der Sandt (Eds.), Focus and natural language processing (pp. 1-10). Heidelberg, Germany: Working Papers of the Institute for Logics and Linguistics.

Birch, S., \& Clifton, C. (1995). Focus, accent, and argument structure: Effects on language comprehension. Language and Speech, 38, 365-391.

Blutner, R., \& Sommer, R. (1988). Sentence processing and lexical access: The influence of the focus-identifying task. Journal of Memory and Language, 27, 359-367. 
Braun, B. (2005). Production and perception of thematic contrast in German. Oxford, UK: Peter Lang Publishing.

Braun, B. (2006). Phonetics and phonology of thematic contrast in German. Language and Speech, 49, 451-493.

Cohen, A., \& 't Hart, J. (1967). On the anatomy of intonation. Lingua, 19, 177-192.

Clark, H. (1977). Bridging. In P. Johnson-Laird \& P. Wason (Eds.), Thinking (pp. 10-63). Cambridge, UK: Cambridge University Press.

Dahan, D., Tanenhaus, M. K., \& Chambers, C. G. (2002). Accent and reference resolution in spoken-language comprehension. Journal of Memory and Language, 47, 292-314.

Fischler, I. (1977). Semantic facilitation without association in a lexical decision task. Memory and Cognition, 5, 335-339.

Foss, D. J. \& Ross, J. R. (1983). Great expectations: Context effects during sentence processing. In G. Flores D'Arcais \& R. J. Jarvella (Eds.), The process of language understanding (pp. 169-191). Chichester, UK: Wiley.

Gussenhoven, C. (2005). Transcription of Dutch intonation. In S. Jun (Ed.), Prosodic typology and transcription: A unified approach (pp. 118-145). Oxford, UK: Oxford University Press.

't Hart, J., Collier, R., \& Cohen, A. (1990). A perceptual study of intonation: An experimentalphonetic approach to speech melody. Cambridge Studies in Speech Science and Communication. Cambridge, UK: Cambridge University Press.

Ito, K., \& Speer, S. (2008). Anticipatory effects of intonation: Eye movements during instructed visual search. Journal of Memory and Language, 58, 541-573.

Ladd, D. R. (1983). Phonological features of intonational meaning. Language, 59, 721-759.

Jaeger, T. F. (2008). Categorical data analysis: Away from ANOVAs (transformation or not) and towards logit mixed models. Journal of Memory and Language, 59, 434-446.

Jackendoff, R. (1972). Semantic interpretation in generative grammar. Cambridge, MA: MIT Press.

Kadmon, N. (2001). Formal pragmatics: Semantics, pragmatics, presupposition, and focus. Oxford, UK: Blackwell.

Lewis, D. (1979). Scorekeeping in a language game. Journal of Philosophical Logic, 8, 339-359.

Lupker, S. J. (1984). Semantic priming without association: A second look. Journal of Verbal Learning and Verbal Behaviour, 23, 709-733.

Moss, H. E., Ostrin, R. K., Tyler, L. K., \& Marslen-Wilson, W. D. (1995). Accessing different types of lexical semantic information: Evidence from priming. Journal of Experimental Psychology: Learning, Memory, and Cognition, 21, 863-883.

Norris, D., Cutler, A., McQueen, J., \& Butterfield, S. (2006). Phonological and conceptual activation in speech comprehension. Cognitive Psychology, 53, 146-193.

Quené, H., \& van den Bergh, H. (2004). On multi-level modeling of data from repeated measures designs: A tutorial. Speech Communication, 43, 103-121.

Rooth, M. (1992). A theory of focus interpretation. Natural Language Semantics, 1, 75-116.

Stalnaker, R. (2002). Common ground. Linguistics and Philosophy, 25, 701-721.

Steedman, M. (2000). Information structure and the syntax-phonology interface. Linguistic Inquiry, 31, 649-689.

Swinney, D., Onifer, W., Prather, P., \& Hirschkowitz, M. (1979). Semantic facilitation across sensory modalities in the processing of individual words and sentences. Memory and Cognition, 7, 159-165.

Tabossi, P. (1988). Accessing lexical ambiguity in different types of sentential contexts. Journal of Memory and Language, 27, 324-340.

Tabossi, P. (1996). Cross-modal semantic priming. Language and Cognitive Processes, 11, 569-576.

Timm, U. (2003). Rot. München, Germany: Deutscher Taschenbuch Verlag. 
1040

Watson, D., Gunlogson, C., \& Tanenhaus, M. (2008). Interpreting pitch accents in on-line comprehension: $\mathrm{H}^{*}$ vs. $\mathrm{L}+\mathrm{H}^{*}$. Cognitive Science, 32, 1232-1244.

Weber, A., Braun, B., \& Crocker, M. (2006). Finding referents in time: Eye-tracking evidence for the role of contrastive accents. Language and Speech, 49, 367-392.

Welby, P. (2003). Effects of pitch accent type and status on focus projection. Language and Speech, $46,53-81$.

Williams, J. N. (1988). Constraints upon semantic activation during sentence comprehension. Language and Cognitive Processes, 3, 165-206. 
APPENDIX 1

Materials with English translations. The last two items were not analysed due to a repetition of the word 'vakantie'

\begin{tabular}{|c|c|c|c|}
\hline Auditory sentence with sentence-final prime & Control prime & Non-contrastive target & Contrastive target \\
\hline Onze buren monteerden een antenne & trapeze & televisie & schotel \\
\hline 'Our neighbours assembled an antenna' & 'trapeze' & ‘television’ & 'dish' \\
\hline De ontsteking werd veroorzaakt door een bacterie & verwonding & ziek & virus \\
\hline 'The inflammation was caused by a bacteria' & 'injury' & 'ill' & 'virus' \\
\hline Er was airconditioning in de cabine & centrale & vliegtuig & kamer \\
\hline 'There was air-conditioning in the cabin' & 'head office' & 'plane' & 'room' \\
\hline De kinderen gooiden met confetti & spaghetti & carnaval & serpentine \\
\hline 'The children threw with confetti' & 'spaghetti' & 'carnival' & 'paper streamer' \\
\hline Mark spiekte tijdens het examen & gefluister & stress & proefwerk \\
\hline 'Mark copied off someone during the exam' & 'whispering' & 'stress' & 'test' \\
\hline In Florida fotografeerde hij een flamingo & beroemdheid & roze & pelikaan \\
\hline 'In Florida he photographed a flamingo' & 'celebrity' & 'pink' & 'pelican' \\
\hline Anne is verkleed als gorilla & kabouter & aap & chimpansee \\
\hline 'Anne is dressed up as a gorilla' & 'gnome' & 'ape' & 'chimpanzee' \\
\hline Roeland repareerde de horloge & insigne & tijd & klok \\
\hline 'Roeland repaired the wrist watch' & 'badge' & 'time' & 'clock' \\
\hline Henk bestelde een jenever & risotto & drank & brandewijn \\
\hline 'Henk ordered a jenever' & 'risotto' & 'drink' & 'brandy' \\
\hline Anke noteerde iets op de kalender & papiertje & jaar & rooster \\
\hline 'Anke wrote something down in her calendar' & 'piece of paper' & 'year' & 'schedule' \\
\hline De keuken ruikt naar kamille & andijvie & thee & lavendel \\
\hline 'The kitchen smells like camomile' & 'endive' & 'tea' & 'lavender' \\
\hline Marlies voerde de kanarie & koala & vogel & parkiet \\
\hline 'Marlies fed the canary' & 'koala' & 'bird' & 'parakeet' \\
\hline De slachtoffers sliepen in de kazerne & taveerne & brandweer & sporthal \\
\hline 'The victims slept in the barracks' & 'tavern' & 'fire brigade' & 'gymnasium' \\
\hline
\end{tabular}


Auditory sentence with sentence-final prime

\section{terrine}

Er waren kokkels in de lagune

'There were cockles in the lagoon'

Marloes ging naar het Lyceum

'Marloes attended the lyceum'

De dierenarts moest naar de manege

'The vet had to go to the stables'

Mijn broer zit bij de marine

'My brother is at the marines'

De sculpturen stonden in het museum

'The sculptures stood in the museum'

De kamelendrijver zag een oase

'The camel-driver saw an oasis'

De hond kauwde op een pantoffel'

'The dog chewed on a slipper'

De huisarts gaf hem een placebo

'The GP gave him a placebo'

Mijn buurman werkte voor de provincie

'My neighbour works for the Province'

De poster hing aan de punaise

'The poster hang from the drawing pin'

Mijn vader draagt een pyjama

'My father wears a pyjama'

Het stel sprak af in de ruine

'The couple agreed to meet at the ruin'

In de lente gingen zij op safari

'In spring they went on safari'
Control prime

Non-contrastive target

Contrastive target

\section{rivier}

water

'water'

school

gebergte

'mountain range'

'school'

savanne

paard

'savanna'

fanfare

'brass band'

noordoosten

'north east'

toeriste

'tourist'

kastanje

'chestnut'

verklaring

'explanationt'

politie

'police'

piano

'piano'

kalkoentje

'little turkey'

pagode

'pagoda'

karate

'karate' 'horse'

boot

'boat'

kunst

'art'

woestijn

'desert'

sloffen

'slippers'

nep

'fake'

land

'country'

prikbord

'notice board'

slapen

'to sleep'

kasteel

'castle'

jungle

'jungle' 'river'

mavo

'lower general

sec. education'

boerderij

'farm house'

luchtmacht

'air force'

archief

'archive'

luchtspiegeling

'illusion'

slippers

'flip-flop'

medicijn

'medicin'

gemeente

'community'

spijker

'nail'

nachthemd

'nightgown'

bunker

'bunker'

trektocht

'hiking tour' 
APPENDIX 1 (Continued)

\begin{tabular}{|c|c|c|c|}
\hline Auditory sentence with sentence-final prime & Control prime & Non-contrastive target & Contrastive target \\
\hline Mijn tante ontving een klein salaris & cadeautje & geld & subsidie \\
\hline 'My aunt received a small salary' & 'small present' & 'money' & 'subsidy' \\
\hline Christel eet het liefst sardine & komkommer & vis & zalm \\
\hline 'Christel preferably eats sardine' & 'cucumber' & 'fish' & 'salmon' \\
\hline Onze zoon houdt van spinazie & sukade & groente & kool \\
\hline 'Our son loves spinach' & 'candied peel' & 'vegetable' & 'cabbage' \\
\hline Hans kocht een stuk suede & verlengsnoer & leer & zijde \\
\hline 'Hans bought a piece of suede' & 'extension lead' & 'leather' & ‘silk’ \\
\hline Zaterdag ging ik naar het theater & orakel & voorstelling & bioscoop \\
\hline 'On Saturday I went to the theatre' & 'oracle' & 'performance' & 'film theatre' \\
\hline Zijn lievelingssmaak was vanille & tomaten & ijs & kaneel \\
\hline 'His favourite taste was vanilla' & 'tomatoes' & 'ice cream' & ‘cinnamon' \\
\hline De socialist imponeerde de elite & projectgroep & rijk & burgers \\
\hline 'The socialist impressed the elite' & 'project group' & 'rich' & 'citizens' \\
\hline De majoor stopte bij de douane & veranda & grens & marechaussee \\
\hline 'The major stopped at the customs' & 'veranda' & 'border' & 'military police' \\
\hline De technicus werkte in de garage & vakantie & auto & hangar \\
\hline 'The technician worked in the garage' & 'holiday' & 'car' & 'hangar' \\
\hline De collega gaat op vakantie & auditie & zon & zakenreis \\
\hline 'The colleague went on holidays' & 'audition' & 'sun' & 'business trip' \\
\hline
\end{tabular}

